\title{
Assessment of short term prognosis in patients with upper gastrointestinal bleeding
}

\author{
Saeid Hashemieh (MD) ${ }^{1}$, Ramtin Moradi (MD) ${ }^{2}$, Davood Karimi Hosseini (MD) ${ }^{3}$ and \\ Habib Malek Pour (MD) 1* \\ ${ }^{1}$ Department of Internal Medicine, Shahid Beheshti University of Medical Sciences \\ ${ }^{2}$ Mashhad Azad University School of Medicine \\ ${ }^{3}$ Stanford University School of Medicine, Palo Alto, CA, USA
}

\section{ABSTRACT}

Upper gastrointestinal bleeding (UGIB) is a medical emergency. There is no precise information of its prevalence and prognosis in patients. The aim of present study was to investigate the prognostic factors of UGIB in patients. In this prospective observational study 75 patients with UGIB referred to Hospital. Demographic and clinical data of them were recorded and analyzed. Mortality rate in first hospitalization was 16\% and in one-month follow up was 4\%. There was no significant association between age and gender with duration of hospitalization and one-month prognosis $(\mathrm{p}>0.05)$. Mortality was associated with acute abdomen and orthostatic hypotension I admission time, peptic ulcer in endoscopic evaluation, active bleeding, ICU admission and need to second endoscopy $(\mathrm{p}<0.05)$. Erosive gastritis, need to emergent surgery and use of NSAIDs significant increase of mortality rate $(\mathrm{p}<0.05)$. It seems admission time signs and symptoms, hemodynamic and coagulation status, endoscopic results and need to re-endoscopic evaluation are more prognostic factors in patients with UGIB.

KEY WORDS: SHORT TERM PROGNOSIS, UPPER GASTROINTESTINAL, BLEEDING

\section{INTRODUCTION}

The UGIB bleeding occurs frequently and is a common cause of hospitalization or inpatient bleeding. Such bleeding results in substantial patient morbidity, mortality and healthcare expense. Ulcer disease is the most common cause of severe UGIB, causing about 40-50\% of cases and UGIB is the most common complication of peptic ulcer disease (Kovacs and Jensen, 2008). The initial management of the patient with UGIB should include evaluation of severity of the hemorrhage, patient resuscitation, a brief medical history and physical examination,

\section{ARTICLE INFORMATION :}

*Corresponding Author:

Received $27^{\text {th }}$ June, 2017

Accepted after revision $27^{\text {th }}$ Sep, 2017

BBRC Print ISSN: 0974-6455

Online ISSN: 2321-4007 CODEN: USA BBRCBA

Thomson Reuters ISI ESC and Crossref Indexed Journal

- NAAS Journal Score 2017: 4.31 Cosmos IF: 4.006

- A Society of Science and Nature Publication, 2017. All rights reserved.

Online Contents Available at: http//www.bbrc.in/

DOI: $10.21786 / \mathrm{bbrc} / 10.3 / 1$ 
and consideration of possible interventions (Lin et al. 2005). This lack of evidence is reflected in the literature. In databases and in product monographs for corticosteroids, peptic ulcer disease and GI bleeding may or may not be described as possible adverse effects (de Abajo et al. 2013).

GI bleeding, bleeding peptic ulcer and perforation are feared complications of peptic ulcer disease, associated with considerable morbidity and mortality (Lanas et al. 2011). In clinical recommendations, an association between corticosteroid use and peptic ulcer has been described as unlikely, and the value of antiulcer prophylaxis has been questioned due to a low bleeding risk (Martinek et al. 2011). Non-steroidal anti-inflammatory drugs (NSAID) use and Helicobacter pylori infection are the most important risk factors for peptic ulcer disease. Bleeding or perforation is also seen as complications to stress ulcers among patients with critical illness in intensive care units. GI bleeding and perforation are assumed to occur when ulcers erode into underlying vessels (Halliday et al. 2010). It is reported a high late as well as early mortality for upper GI bleeding, with very poor longer term prognosis following bleeding due to malignancies and varices. Aetiologies with the worst prognosis were often associated with high levels of social deprivation (Roberts et al. 2012).

The aetiology of hemorrhage can be broadly considered to be non-variceal or variceal in origin. In the upper gastrointestinal haemorrhage accounts for85\% of presentations, the major causative lesion being peptic ulcer disease, followed by erosive diseases such as oesophagitis, gastritis and duodenitis (Jairath \& Barkun, 2012). Risk factors for developing upper gastrointestinal hemorrhage include old age, socio-economic disadvantage, co-morbidities such as chronic renal disease, Helicobacter pylori infection and several pharmaceutical agents including NSAIDS, aspirin, cyclo-oxygenase (COX) 2 inhibitors and anticoagulants. The remaining presentations (10-15\%) are secondary to variceal hemorrhage in patients with liver cirrhosis (Holcomb et al. 2015).

Coagulopathy exacerbates bleeding and should be corrected with blood products. Massive bleeding mandates emergency endoscopy. Emergency endoscopy is performed as soon as the patient is stabilized after initial resuscitation. In patients with exigent bleeding, endoscopy can be performed during resuscitation (Button et al. 2011). Local studies indicate that as the incidence of upper GI bleeding has increased over time (Hearnshaw et al. 2010). There is also current interest in whether prognosis for emergency disorders varies according to the day of admission, the size of hospital and the distance travelled to hospital although little has been reported about these for upper GI bleed- ing (Shaheen et al. 2009). So, the main objective of this study was to establish short term prognosis in patients with UGI bleeding in 1 month follow-up period.

\section{MATERIAL AND METHODS}

This prospective observational study was done to assess short term prognosis in 75 patients with upper gastrointestinal bleeding referred to the Imam Husein Hospita, (Tehran, Iran) during the 2015-16. The demographic information was collected using check list based on patient's background, Para clinic information, hospitalization and follow-up data. Correlation between sex, gender, age, disease and medication background, gastrointestinal disorder, smoking or alcohol drinking, blood factors (hemoglobin, PT, PTT, INR and platelet) and endoscopic ulceration are determined at the arrival and after 1 month. Data is analyzed by repeated measure one-way analysis of variance (ANOVA) using SPSS 16.0 for Windows (SPSS, Inc., Chicago, IL, USA). For treatment showing a main effect by ANOVA, means compared by Tukey-Kramer test. $\mathrm{P}<0.05$ was considered as significant differences between treatments.

\section{RESULT AND DISCUSSION}

As seen in the current study, among 75 patients, 54 male $(72 \%)$ and 21 women (28\%) were include into the study. The mean age of the patients was $61.2 \pm 18.6$ years old $(\mathrm{P}=0.4)$.in this study, $37(49.3 \%)$ had hematoma while 46 (61.3\%) had melena, 11 (14.7\%) Hematochezia and 27 (36\%) with active bleeding were referred to the hospital. In the initial investigation the mean blood pressure and diastolic pressures were $116.1 \pm 19.2$ and $69.8 \pm 23.4$ $\mathrm{mmHg}$, respectively. Mean heart rate was $81.2 \pm 27.7$ / min. the clinical results of the patients included into the study is presented in table 1 . According to the data, the man $\mathrm{HB}$ at the beginning and end of the study were 9.3 \pm 2.9 and $9.8 \pm 2.01 \mathrm{mg} / \mathrm{dl}$, respectively. The mean PT, PTT and INR were $14.7 \pm 8.7,31.9 \pm 25.2$ and $1.5 \pm 1.4$, respectively.

The patient's distribution based on disease background is presented in table 2. According to the data, Hypertension and Cardiovascular disease were the most frequent among them. Also, ulcer was the prominent digestive disease 27 (36\%). For family background for gastrointestinal disease, GI cancer 4 (5.3\%) was the most report.

Based on the endoscopic observation, clean base and gastritis were the more problem 23 (30.7\%) and 22 $(29.3 \%)$ in the patients.

In this study, 4 patients (5.3\%) needed for urgency surgery and 33 (44\%) for packed cell. During the study, 


\begin{tabular}{|c|c|c|c|}
\hline Factor & Minimum & Maximum & Mean \pm Sd \\
\hline $\mathrm{Hb}$ (at arrival) (mg/dl) & 2.9 & 16 & $9.3 \pm 2.9$ \\
\hline $\mathrm{Hb}$ (after treatment) $(\mathrm{mg} / \mathrm{dl})$ & 6.8 & 15.7 & $9.8 \pm 2.01$ \\
\hline PT & 1.3 & 50 & $14.7 \pm 8.7$ \\
\hline PTT & 1 & 120 & $31.9 \pm 25.2$ \\
\hline INR & 1 & 9.3 & $1.5 \pm 1.4$ \\
\hline Platelet & 31500 & 479000 & $213200 \pm 111800$ \\
\hline
\end{tabular}

\begin{tabular}{|l|c|c|c|}
\hline \multicolumn{4}{|l|}{ Table 2. The patients distribution based on disease background } \\
\hline Factor & N (\%) & $\begin{array}{c}\text { Family background for } \\
\text { Gastrointestinal disease }\end{array}$ & N (\%) \\
\hline Disease background & & Ulcer & $2(2.7)$ \\
\hline Diabetes & $31(41.3)$ & Gastrointestinal cancer & $4(5.3)$ \\
\hline Hyperlipidemia & $17(22.7)$ & Intestinal ulcers & $2(2.7)$ \\
\hline Hypertension & $41(54.7)$ & Medication Background & \\
\hline Cardiovascular disease & $41(54.7)$ & NSAID & $20(26.7)$ \\
\hline Cirrhosis & $8(10.7)$ & SSRI & $13(17.3)$ \\
\hline Hepatitis & $5(6.7)$ & Warfarin & $10(13.3)$ \\
\hline Digestive disorders & & Steroid & $2(2.7)$ \\
\hline Ulcer & $27(36)$ & Opioid therapy & \\
\hline Intestinal ulcers & $8(10.7)$ & Alcohol & $16(21.3)$ \\
\hline Gastrointestinal cancer & $6(8)$ & Opiates & $31(41.3)$ \\
\hline Gastrointestinal bleeding & $8(10.7)$ & Smoking & $5(6.7)$ \\
\hline & & Methadone & $1(1.3)$ \\
\hline
\end{tabular}

16 patients needed for hospitalization $(21.3 \%)$ in the ICU. $6(8 \%)$ of them had bleeding and 11 (14.7\%) subsequent endoscopy. Hospitalization period was $5.5 \pm 2.5$ days and 12 deaths during hospitalization and 3 deaths in 1 month follow-up were reported. After a month follow-up, digestive signs 32 (50.8\%), bleeding 32 (50.8\%), sever moral 2(3.1\%), re-endoscpoy 2(3.1\%), re-hospitalization 2(3.1\%), and death 3(3.4\%) were recorded. No significant difference detected between sex, age, family background, medication, Hematochezia, hematoma and melena before and after the study $(\mathrm{P}>0.05)$. No significant difference observed in group aged $<60$ and $>60$ years old in mentioned factors $(\mathrm{P}>0.05)$.

According to the results, a significant correlation observed between blood pressure and bad moral $(\mathrm{P}<0.001)$, GI bleeding $(\mathrm{P}=0.018)$, alcohol $(\mathrm{P}=0.04)$, Opium administration $(\mathrm{P}=0.000)$, NSAIDs $(\mathrm{P}=0.036)$, ulcer incidence in primary endoscopy $(\mathrm{P}=0.003)$, Gastritis $(\mathrm{P}=0.008)$, emergency surgery $(\mathrm{P}=0.000)$, ICU care $(\mathrm{P}=0.000)$, re-bleeding $(\mathrm{P}=0.010)$ and need for subsequent endoscopy $(\mathrm{P}=0.000)$. A correlation exist between opium administration in 1 month follow-up and endoscopic ulcer $(\mathrm{P}=0.07)$. A significant correlation reported between death and peritonitis $(\mathrm{P}=0.046)$, hypotension
$(\mathrm{P}=0.053)$, gastric ulcer in endoscopy $(\mathrm{P}=0.04)$, bleeding $(\mathrm{P}=0.023)$, ICU care $(\mathrm{P}=008)$ and no differences found in re-endoscopy $(\mathrm{P}=027)$, NSAIDs $(\mathrm{P}=056)$, gastritis $(\mathrm{P}=073)$ and emergency surgery $(\mathrm{P}=053)$.

According to the results, mortality rate in first hospitalization was $16 \%$ and in one-month follow up was $4 \%$. There was no significant association between age and gender with duration of hospitalization and onemonth prognosis. Mortality was associated with acute abdomen and orthostatic hypotension I admission time, peptic ulcer in endoscopic evaluation, active bleeding, ICU admission and need to second endoscopy. Erosive gastritis, need to emergent surgery and use of NSAID

\begin{tabular}{|c|c|}
\hline Endoscopic results & $\mathrm{N}(\%)$ \\
\hline Pigmented ulcer Pigmented ulcer & $2(5.3)$ \\
\hline Clean base & $23(30.7)$ \\
\hline Gastritis & $22(29.3)$ \\
\hline Tearing & $2(2.7)$ \\
\hline Gastric varices & $7(9.3)$ \\
\hline Visiblessle ulcer & $8(10.7)$ \\
\hline
\end{tabular}


significant increase of mortality rate. It seems admission time signs and symptoms, hemodynamic and coagulation status, endoscopic results and need to re-endoscopic evaluation are more prognostic factors in patients with UGIB.

In a study, Lanas et al. (2011) on 2660 patients (64.7\% men; mean age 67.7 years) significant differences reported on across countries in bleeding continuation / re-bleeding (range: $9-15.8 \%)$ or death $(2.5-8 \%)$ at 30 days were explained by clinical factors (number of comorbidities, age $>65$ years, history of bleeding ulcers, in-hospital bleeding, type of lesion or type of concomitant medication). Other factors (country, size of hospital, profile of team managing the event, endoscopic and/or pharmacological therapy received) were not able to affect these outcomes (Loperfido et al. 2009). Risk factors that have been previously identified to be predictive of bleeding continuation and re-bleeding include presence of comorbidities outcomes (Loperfido et al. 2009) endoscopy-observed highrisk stigmata of bleeding; worse health status at admission; bleeding from a peptic ulcer ( Viviane and Alan, 2008) a finding of bright blood during rectal examination and in nasogastric tube aspirate; smoking; failure to use PPIs postendoscopy; postendoscopy use of intravenous or low molecular-weight heparins and low endoscopist experience (Travis et al. 2008).

A number of these previously identified predictive factors were confirmed in UGIB (i.e. presence of comorbidities, bleeding from a duodenal ulcer), and a number of new predictors of bleeding continuation/ re-bleeding were characterized: older age ( $>65$ years), presentation with haematemesis and a history of UGIB at baseline (Button et al. 2011). Previously characterized predictors of mortality include older age; presence of, and increasing number of, comorbidities; continued bleeding and / or re-bleeding and a finding of bright blood in the nasogastric tube aspirate (Marmo et al. 2010). The predictive validity of older age and the presence of comorbidities were confirmed in UGIB; in fact, the presence of comorbidities was by far the strongest predictor of mortality in this patient population. Other factors identified to be significantly predictive of mortality in this study were presentation with clinical symptoms of acute upper GI bleeding and alcohol abuse (Shaheen et al. 2009).

The overall rate of deaths due to GI complications and the rate of deaths associated with NSAID/aspirin use reported are lower than some frequently quoted estimates from previous studies, despite the fact that our figures include both upper and lower GI complications and also refer to low-dose aspirin use (Hawkey and Langman, 2003).

There are a number of reasons that may account for some of the discrepancies observed in the studies: variation in prescribing practice by country; differences in the extent of NSAID use and in the co-prescription of gastroprotective drugs; decreasing GI complication rates; and differences in study methodologies. Our data would imply a lower NSAID consumption in Spain compared with other countries. However, the annual NSAID prescription rates in Spain are relatively high (35.4 million) (Van Leerdam et al. 2003) and are proportionally greater than rates reported in the United Kingdom and $50 \%$ of those reported in the United States (70 million), despite Spain's smaller population. In addition, the rate of NSAID use among adults in Spain (20.6\%) is similar than that determined in the United States (Estudio, 2000). Upper GI bleeding is one of the most important emergency disorders with high rates of mortality during the acute phase. Longer term increased risk of mortality is partly due to very poor prognosis for malignancy and variceal etiologies; although it also reflects an impact of high levels of social deprivation and chronic co-morbid disease among people with upper GI bleeding (Roberts et al. 2012).

Survival over the three years was substantially poorer than in the general population for most etiologies of bleeding, with the possible exception of 'complications of analgesics, antipyretics and anti-inflammatory drugs' and duodenal ulcers, which were both less prevalent among deprived quintiles than most of the other etiologies. Relative survival was worse for duodenal ulcer than for gastric ulcer in the first few months after admission, but it was better than for gastric ulcer bleeds in the longer term. This finding is consistent with a large single-center study of surgery for peptic ulcer which found increased longer term mortality for gastric ulcer but not for duodenal ulcer (Stae“l von Holstein et al. 1997). In conclusion it seems admission time signs and symptoms, hemodynamic and coagulation status, endoscopic results and need to re-endoscopic evaluation are more prognostic factors in patients with UGIB.

\section{REFERENCES}

Button LA, Roberts SE, Evans PA, et al. 2011 Hospitalized incidence and case fatality for upper gastrointestinal bleeding from 1999 to 2007: a record linkage study. Aliment Pharmacol Ther 2011; 33: 64-76.

Button LA, Roberts SE, Evans PA, Goldacre MJ, Akbari A, Dsilva R, Macey S, Williams JG 2011. Hospitalized incidence and case fatality for upper gastrointestinal bleeding from 1999 to 2007: a record linkage study. Aliment Pharmacol Ther 33: 64-76

Carmona L. Estudio 2000 EPISER. Madrid: Spanish Society of Rheumatology; 141-54.

De Abajo FJ, Gil MJ, Bryant V, et al.2013 Upper gastrointestinal bleeding associated with NSAIDs, other drugs and interactions: a nested case-control study in a new general practice database. Eur J Clin Pharmacol 69:691-701. 
Halliday HL, Ehrenkranz RA, Doyle LW.2010 Early ( $<8$ days) postnatal corticosteroids for preventing chronic lung disease in preterm infants. Cochrane Database Syst Rev (1):CD001146.

Hawkey CJ, Langman MJ 2003 .Non-steroidal anti-inflammatory drugs: Overall risks and management. Complementary roles for COX-2 inhibitors and proton pump inhibitors. Gut 52(4):600-8.

Hearnshaw SA, Logan RF, Lowe D, Travis SP, Murphy MF, Palmer KR. 2010 Use of endoscopy for management of acute upper gastrointestinal bleeding in the UK: results of a nationwide audit. Gut 59: 1022-9.

Holcomb, J.B., Tilley, B.C., Baraniuk, S. et al. (2015) Transfusion of plasma, platelets, and red blood cells in a 1:1:1 vs a 1:1:2 ratio and mortality in patients with severe trauma: the PROPPR randomized clinical trial. JAMA, 313, 471-82.

Kovacs TOG, Jensen DM. 2008 The short-term medical management of non-variceal upper gastrointestinal bleeding. Drugs 68 (15): 2105-2111.

Lanas A, Garcia-Rodriguez LA, Polo-Tomas M, et al. 2011 The changing face of hospitalisation due to gastrointestinal bleeding and perforation. Aliment Pharmacol Ther 33:585-91.

Lin HJ, Lo WC, Cheng YC, et al. 2006 Role of intravenous omeprazole in patients with high- risk peptic ulcer bleeding after successful endoscopic epinephrine injection: a prospective, randomized, comparative trial. Am J Gastroenterol 101: 500-5.

Loperfido S, Baldo V, Piovesana E, et al. 2009 Changing trends in acute upper-GI bleeding: a population-based study. Gastrointest Endosc 70: 212-24.
Marmo R, Koch M, Cipolletta L, et al. 2010 Predicting mortality in non-variceal upper gastrointestinal bleeders: validation of the Italian PNED score and prospective comparison with the Rockall score. Am J Gastroenterol 2010; 105: 1284-91.

Martinek J, Hlavova K, Zavada F, et al. 2010 A surviving mythcorticosteroids are still considered ulcerogenic by a majority of physicians. Scand J Gastroenterol 45:1156-61.

Roberts SE, Button LA, Williams JG (2012) Prognosis following Upper Gastrointestinal Bleeding. PLoS ONE 7(12): e49507. doi:10.1371/ journal.pone.0049507

Shaheen AA, Kaplan GG, Myers RP. 2009 Weekend versus weekday admission and mortality from gastrointestinal hemorrhage caused by peptic ulcer disease. Clin Gastroenterol Hepatol 7: 303-10.

Stae"l von Holstein C, Anderson H, Ahsberg K, Huldt B (1997) The significance of ulcer disease on late mortality after partial gastric resection. Eur J Gastroenterol Hepatol 9: 33-40.

Travis AC, Wasan SK, Saltzman JR.2008 Model to predict rebleeding following endoscopic therapy for non-variceal upper gastrointestinal hemorrhage. J Gastroenterol Hepatol 23: 1505-10.

Van Leerdam ME, Vreeburg EM, Rauws EA, et al. 2003 Acute upper GI bleeding: Did anything change? Time trend analysis of incidence and outcome of acute upper GI bleeding between 1993/1994 and 2000. Am J Gastroenterol;98(7):1494-9.

Viviane A, Alan BN. 2008 Estimates of costs of hospital stay for variceal and nonvariceal upper gastrointestinal bleeding in the United States. Value Health 11: 1-3. 